These experiments suggest that the hydrogen bonds in the DNA molecule are broken by low doses of $X$-rays. The molecule becomes more flexible and loses only little of its viseosity. Breaks of the nucleotide chain leading to a further decrease of the viscosity seem to occur mostly after higher doses. DNA, extracted from the thymus $3-6 \mathrm{hr}$. after $1,000-\mathrm{r}$. whole-body irradiation, shows a considerable change in viscosity decreasing to 50 per cent of the control ${ }^{4}$. This degraded DNA, prepared from the thymus of irradiated animals according to Kirby, does not, however, show any formaldehyde reaction at all. There is no difference in the absorption spectrum before and after incubation with formaldehyde, whereas after heating, a shift of the maximum and an increase of the extinction can be observed. Here, after irradiation in vivo, the decrease in viscosity is a much more sensitive method than the formaldehyde reaction. This supports the idea that ionizing radiation destroys the DNA in vivo by quite different mechanisms than in vitro.

Radiological Institute,

University of Freiburg i. Br.

'Alexander, P., Lett, J. T., Moroson, M., and Stancay, K. A., Immediate and 'Low Level Effects of Ionizing Radiation, 47 '(Taylor

¿Sarkar, N. K., and Dounce, A. L., Biochim. Biophys. Acta, 49, 160 (1961).

${ }^{3}$ Fraenkel-Conrat, H., Biochim. Biophys. Acta, 15, 307 (1954).

+ Hagen, U., Strahlentherapie, 116, 385 (1961).

${ }^{5}$ Lett, J. T., and Alexander, P., Rad. Res., 15, 159 (1961).

6irby, K. \$., Biochem. J., 66, 495 (1957).

\section{Accelerated Collagen Formation and Histamine}

IT has recently been demonstrated that reparatively growing tissues in skin wounds in the rat produce histamine at a high rate as a result of increased activity of histidine decarboxylase ${ }^{1}$. Further, the rate of repair, as measured by the tensile strength of the healing wound in situ, can be augmented or retarded, respectively, by artificial increase or inhibition of the histamine-forming capacity of the growing tissues. In these experiments the histamineforming capacity was increased by injections of the histamine liberator $48 / 80$, which depletes the skin of its histamine content and concomitantly raises the skin level of histidine decarboxylase. Extracellular histamine, derived from injected 'longacting histamine', had no detectable effect on growth in healing. It was concluded that only intracellularly formed 'nascent' histamine is active in promoting certain types of growth ${ }^{2}$.

Because collagen is a principal component of reparatively growing tissues in skin wounds, and the tensile strength in particular depends on collagen ${ }^{3}$, it seemed interesting to determine the rate of collagen formation under conditions of increased histamine. forming capacity effected by injections of $48 / 80$.

Samples of granulation tissue were obtained for study from polyvinyl sponges ('Ivalon') implanted subcutaneously in rats of both sexes from a closed colony bred at our Institute and weighing 200 $300 \mathrm{gm}$. Under ether anæsthesia an incision was made in the mid-line of the back and two sponges were placed under the skin of one side of the back. On the fifth day after the implantation the sponges were removed and collagen content assessed by measuring the constituent amino-acid hydroxyproline ${ }^{4}$. These samples served as controls. About two weeks later each rat received $48 / 80$ (1 mgm./kgm./day) intraperitoneally on three successive days. The activation of histidine decarboxylase resulting from this treatment was discovered by Schayer et al..$^{5}$, and fully confirmed in this laboratory ${ }^{1}$. On the next day two polyvinyl sponges were again implanted subcutaneously on the opposite side of the back and were removed for examination five days later.

In experiments on 15 rats the formation of collagen was enhanced by the pretreatment with $48 / 80$, as judged from the hydroxyproline content. The granulation tissue formed contained on the average 55 per cent more collagen than the controls, mean \pm standard error of mean, $55 \pm 9.9$ per cent.

These results provide further support of a connexion between certain types of rapid growth and histidine decarboxylase ${ }^{6,7}$.

N. SANDBERG

Institute of Physiology,

University of Lund. Sweden.

' Kahlson, G., Nilsson, K., Rosengren, F., and Zederfeldt, B., Lancet, ii, $230(1960)$.

Kahlson, G., Perspect. Biol. Med., 5, 179 (1962).

"Sandberg, N., and Zederfeldt, B., Acta Chir. Scand. (in the press).

'Neuman, R. E., and Logan, M. A., J. Biol. Chem., 184, 299 (1950) Schayer, R. W., Rothschild, Z., and Bizony, P., Amer. J. Physiol. $196,295(1959)$.

${ }^{8}$ Kahlson, G., Lancet, i, 67 (1960).

${ }^{7}$ Kahlson, G., and Rosengren, E., Nature, 184, 1238 (1959).

\section{Virginiamycin as an Antibiotic for Poultry Feeds}

Antibionics are widely used at low lovels in commercial feeds to improve the early growth-rate of chickens and turkeys. The amount of response obtained from these drugs appears to be related to the nature and density of the microflora present in the feed and environment ${ }^{1}$.

Antibiotics now used in manufactured feeds inhibit both Gram-positive and Gram-negative organisms ('broad spectrum') or, more specifically, the common Gram-positive pathogens ('narrow spectrum'). The new antibiotic, virginiamycin ${ }^{2-4}$, is mainly active against Gram-positive organisms, but actually consists of three components having different spectra of activity. To evaluate this antibiotic for use in feed, it was compared with terramycin and zinc bacitracin, which have 'broad' and 'narrow' spectra, respectively, and are typical of the antibiotics used currently in commercial feods.

(1) Virginiamycin, terramycin and zine bacitracin were incorporated in the feed at low and high levels and fed to day-old, Cobb's strain, White Rock chicks reared in batteries. Four replicate pens of ten cockerels each were used for all treatments. Chicks were weighed individually at the beginning of the experiment and distributed equally by weight between the various pens. A practical starter-grower feed typical of commercial formulations which more than satisfied the N.R.C. nutritive requirements for chicks $^{5}$ was used as the basal ration. Pens were equipped with electrically heated brooders, raised wire floors and fluorescent lights.

At both four and eight weeks, all lots of birds which received antibiotics weighed more than the control lot (Table 1). These differences were significant $(P<0.01)$, except for the high levels of terramycin and zine bacitracin for both periods and the low level of virginiamycin at four weeks. 